\title{
Are there any differences in the assessment of quality of life when children score the importance of what is asked to them?
}

\author{
Alfonso Urzúa Morales, Ps.D., ${ }^{a}$ Constanza Julio Toro, B.S., ${ }^{a}$ \\ Daniela Páez Ramírez, B.S., ${ }^{a}$ Javiera Sanhueza González, B.S., ${ }^{a}$ \\ and Alejandra Caqueo Urízar, Ps.D. ${ }^{b}$
}

\begin{abstract}
Introduction. There are no studies that enable to explore the impact that might have the scoring of the importance that children assign to each dimension that encompass the assessment of their quality of life (QoL).

Objective. To analyze the influence of the importance assigned by children to the different spheres of their lives when having to assess their quality of life.

Material and Methods. Correlational, crosssectional design. The modified KIDSCREEN-27 questionnaire was used to evaluate the importance assigned by the child to each dimension. Results. A total of 300 schoolboys and 300 schoolgirls, with an average age of 12 years old, were evaluated. The dimension with the highest score was Peers, and the one with the lowest was Psychological well-being, both in the raw evaluation as in the weighted by importance ranking. In girls, the Physical well-being dimension scored the lowest. The dimensions Parent relations and School environment scored the highest in younger students. In girls, differences were found in the dimension that scored the lowest when they weighted the importance of the dimension; shifting the dimension with the lowest score from Psychological well-being to Physical well-being. Conclusion. There are differences in the perception of quality of life between boys and girls, the types of schools they attend and the different ages, which do not change when being weighted by importance.

Key words: quality of life, self-report, importance ,assessment.
\end{abstract}

http:/ /dx.doi.org/10.5546/aap.2013.98

E-mail:

alurzuacn@ucn.cl

Conflict of interest:

None.

This article is the result of a study funded by the National Commission for Scientific and Technological Research (CONICYT) of Chile through project FONDECYT 11100090.

Datereceived:05-08-2012 Dateaccepted:10-04-2012 childhood, it includes the perception of physical, psychological and social well-being within a specific cultural context according to the evolutionary development and individual differences, ${ }^{3}$ taking into account the ability to fully participate in physical, social, psychosocial activities and roles as appropriate to their age. ${ }^{4}$ This assessment should be administered as a self-report because the child's perception of vital events does not necessarily match that of an adult, ${ }^{5}$ since both have different life experiences and priorities and do not always share the same meaning of health and disease ${ }^{6}$ nor their perception regarding meeting their own needs.

Investigations about quality of life in children and adolescents in Latin America $^{7}$ are scarce and they are mainly focused on describing and analyzing factors related to the quality of life of the schooled population,, $8-10$ the effect of the health-disease status, ${ }^{11-15}$ or the study of instruments. ${ }^{16-22}$ Such studies do not look into the cognitive processes related to the processing of information underlying this assessment, even though the specific ways of interpreting an individual's own reality would impact on the positive or negative assessment made by the individual regarding his/her quality of life, beyond cultural standards, his/her resources or, even his/her own personality.

One of these processes is the scoring of the importance that people assign to each of the dimensions influencing quality of life perception. ${ }^{23}$ In such a context, the aim of the present research is to analyze the differences in the quality of life assessment 
when including the child's scoring of the importance for each dimension.

\section{PATIENTS AND METHODS Participants}

The study was conducted in the city of Antofagasta, Chile, during 2011. The type of method used was availability sampling, assuming a similar distribution by gender, age and type of school (public, subsidized and private). Of a population of 26,166 children, aged 10 to 14 years old, at least 600 were interviewed because this sample size allows for tests to reach a power of 0.97 and for the design to be sensitive to differences. ${ }^{24} \mathrm{In}$ clusion criteria were that children had to be 1014 years old and have their parents' consent to participate in the research. All children gave their assent to participate.

\section{Instruments}

The KIDSCREEN-27 questionnaire for children aged 8-18 years, which encompasses five dimensions ${ }^{25}$ (Table 1), was used. This questionnaire has psychometric properties that are adequate for its use in the studied population. ${ }^{21}$

In order to evaluate the degree of importance assigned by participants to each of the evaluated dimensions, a question was added to each question in the KIDSCREEN-27 survey asking children to score the importance of the dimension being evaluated by assigning 1 to 5 points to it, according to the importance he/she assigned to each area of his/her life. For example, after the question: "Have you gone out to play or have fun with your friends?" we asked: "How important is it for you to go out to play or have fun with your friends?" Answer options ranged from not important at all to very important.

To estimate the weighted score for each question, the raw score (RS) obtained in the question (1-5 points) was multiplied by the score of impor- tance assigned to such question, thus obtaining scores weighted by importance (SWIs). Then the values of the different dimensions were estimated by taking into account the questions in each dimension. In order to improve data interpretation, and given that the syntax of correction for RSs provides scores ranging from 0 to 100 for each dimension, SWIs were converted to a 0-100 scale so as to set up a proportional ratio of the included scores. This system of assigning a score to importance has been theoretically discussed and its usefulness demonstrated. ${ }^{34}$ Before administering the questionnaire to the total sample, it was tested using a group cognition technique with two courses from public schools, with an age range similar to our sample, in order to test the degree of understanding of each item, which were completely understood by all the children evaluated.

\section{Procedures}

Once the study was approved by the Ethics Committee of the Universidad Católica del Norte and by the National Commission for Scientific and Technological Research of the Government of Chile (Comisión Nacional Científica y Tecnológica del Gobierno de Chile, CONICYT), parents were requested to authorize the participation of their children by signing an informed consent in each school. The questionnaire was administered collectively, inside the classrooms, and lasted 20-45 minutes. Information was entered into a database using SPSS 17.0.

Mean and standard deviation (SD) values were estimated for each quality of life dimension assessed, both for RSs and SWIs. Given that RSs and SWIs are not comparable, it was analyzed whether there were variations in the differences reported in mean comparisons using a Student's $t$ test for gender, and an ANOVA test for the different age ranges and types of school with RSs and SWIs.

TABLE 1. Quality of life dimensions included in the KIDSCREEN-27 questionnaire

\begin{tabular}{ll}
\hline Dimension & Assessment area \\
\hline Physical well-being & Physical activity, feeling of energy and physical condition \\
Psychological well-being & Positive emotions and satisfaction with life and feelings of emotional balance \\
Parent relations and autonomy & $\begin{array}{l}\text { Relationship with parents, the atmosphere at home, and feelings of being old enough to } \\
\text { become independent and the degree of satisfaction with financial resources }\end{array}$ \\
Social support and peers & $\begin{array}{l}\text { It examines the natural way of relating to other children/adolescents } \\
\text { School environment }\end{array}$ \\
& $\begin{array}{l}\text { Self-perception regarding their cognitive capacity, learning and concentration and } \\
\text { feelings about school }\end{array}$ \\
\hline
\end{tabular}




\section{RESULTS}

A total of 800 informed consents were distributed among parents, of which only 640 were returned duly completed and signed. Out of the 640 authorized children, only 600 signed the written consent in advance because the remaining 40 students had not attended classes on the day the questionnaire was administered. Fifty percent of the 600 children were girls. The age range was 10-14 years old, with an average age of 12 years old (Table 2).

Table 3 shows mean values per dimension for the total sample and by gender, both for RSs and SWIs.

For the total sample, the dimension with the best score was Peers while the dimension with the lowest score was Psychological well-being. This is also seen when using RSs and SWIs. When dividing the sample by gender, the same is observed in boys for both types of scores, but among girls there is a change in the lowest score dimension, which shifts from Psychological well-being to Physical well-being when weighted by importance.

The analysis of mean differences between boys and girls shows that the mean value in boys is higher than in girls regarding Physical well-being, considering both RSs $\left(\mathrm{t}_{(596)}=6.345 ; p<0.00\right)$ and SWIs $\left(\mathrm{t}_{(593)}=4.926 ; p<0.01\right)$. Likewise, the mean value in girls is higher than that in boys in the dimension
Peers, also considering RSs $\left(\mathrm{t}_{(597)}=-2.575 ; p<0.01\right)$ and SWIs $\left(\mathrm{t}_{(595)}=-3.338 ; p<0.05\right)$.

Table 4 shows mean values in the dimensions, both for RSs and SWIs by age.

At 12,13 and 14 years old, the dimension that scored the highest for both types of scores was Peers. This is different for 11 year old students, given that the highest score dimension was School environment, but when weighted by importance, Peers was again the highest scoring dimension. The dimension scoring lowest at all ages by RS was Psychological well-being; however, once weighted by importance, the dimension with the lowest score was Physical well-being.

Based on RSs, when comparing mean values of dimensions among ages, statistically significant differences are found in the dimensions Physical well-being $\left(F_{(3.594)}=14.816 ; p<0.01\right)$, Psychological well-being $\left(F_{(3.594)}=4.745 ; p<0.05\right)$, Parents relations $\left(F_{(3.594)}=6.561 ; p<0.01\right)$, and School environment $\left(F_{(3.595)}=12.452 ; p<0.01\right)$.

The Physical well-being dimension shows a slow decrease in the mean value as age increases. The mean value in 10-11 year old children is significantly higher than in 13 year old students $(p<0.05)$ and 14 year old students $(p<0.01)$, as in the 12-13 year old group which is higher than in 14 year olds ( $p<0.011$ in both cases).

TABLE 2. Distribution of participants by gender, age and type of school

\begin{tabular}{lccccccc}
\hline & \multicolumn{4}{c}{ Age (years) } & \multicolumn{3}{c}{ Type of school } \\
& $\mathbf{1 0 - 1 1}$ & $\mathbf{1 2}$ & $\mathbf{1 3}$ & $\mathbf{1 4}$ & Public & Subsidized & Private \\
\hline Boys & 64 & 67 & 82 & 87 & 100 & 100 & 100 \\
Girls & 53 & 77 & 57 & 113 & 100 & 100 & 100 \\
Total & 117 & 144 & 139 & 200 & 200 & 200 & 200 \\
\hline
\end{tabular}

TABLE 3. Raw and weighted score means by quality of life dimensions for the total sample and by gender

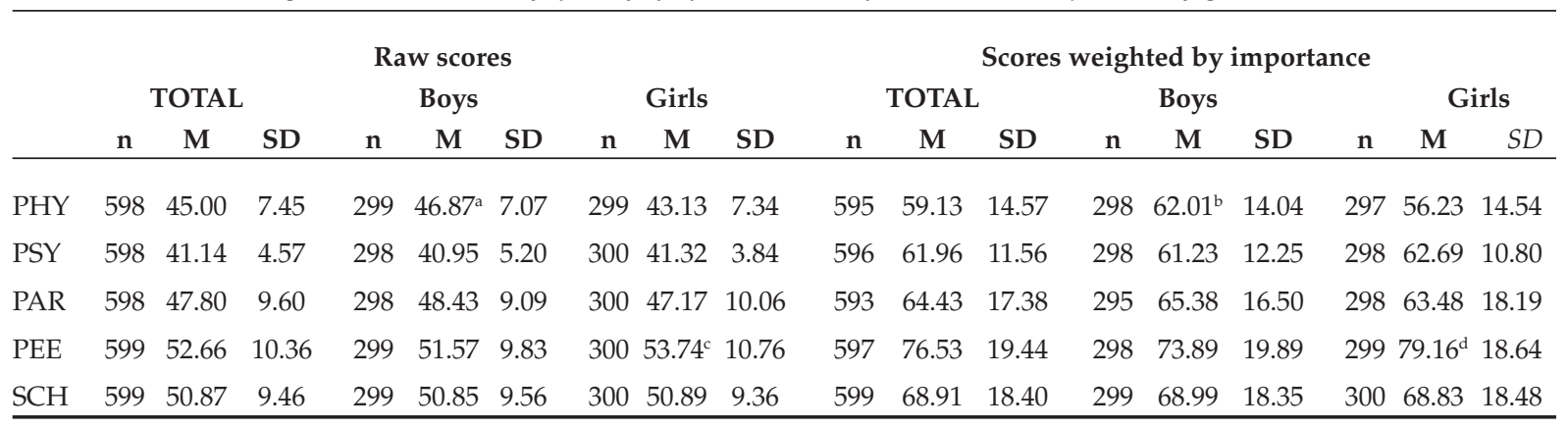

PHY: physical dimension; PSY: psychological dimension; PAR: parents; PEE: peers; SCH: school; asignificantly higher mean score than in girls with a significance level of 0.00 ; ${ }^{b}$ significantly higher mean score than in girls with a significance level of 0.01 ; 'significantly higher mean score than in boys with a significance level of 0.01 ; ${ }^{\mathrm{d}}$ significantly higher mean score in boys with a significance level of 0.05 . 

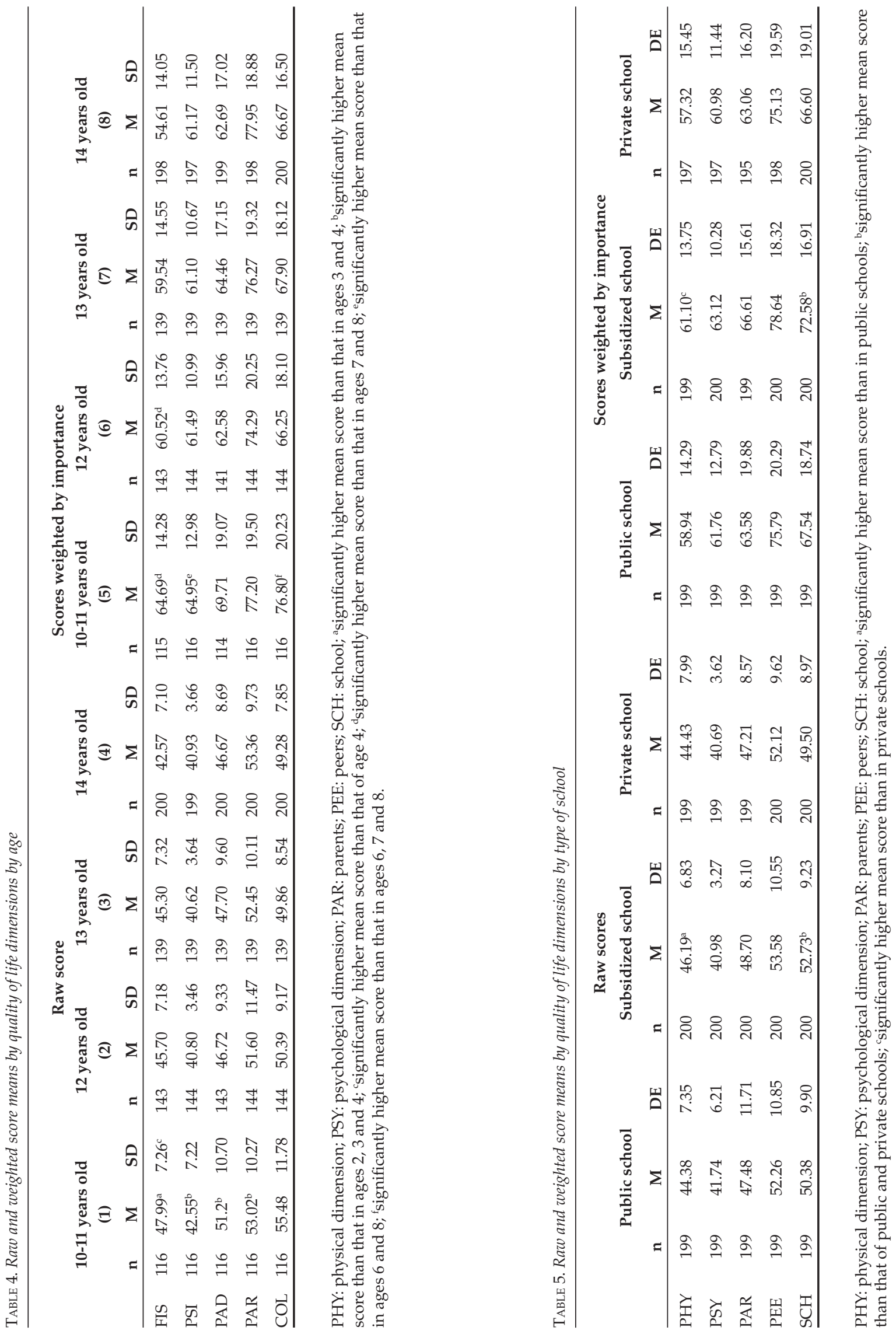
The Psychological well-being dimension shows a significantly higher mean value in 10-11 year old children than in 12 year old children $(p>0.05)$, 13 year old children $(p<0.05)$, and 14 year old children $(p<0.05)$.

The Peers dimension also shows a mean value significantly higher in 10-11 year old children than in 12 year old children $(p>0.05), 13$ year old children $(p<0.05)$, and 14 year old children $(p<0.01)$.

In the School environment dimension, the mean value in 10-11 year old children is significantly higher than in other age groups $(p<0.01$ in all comparisons).

Based on SWIs, the difference of mean values among ages is statistically significant in the following dimensions: Physical well-being $\left(F_{(4.590)}=10.772 ; p<0.01\right)$, Psychological well-being $\left(F_{(4.591)}=2.915 ; p<0.05\right)$, Parents relations $\left(F_{(4.588)}=3.835 ; p<0.05\right)$, and School environment $\left(F_{(4.594)}=7.581 ; p<0.01\right)$.

In the Physical well-being dimension, mean values steadily decrease as age increases, with a mean value in the 10-11 year old group significantly higher than in the 13 year old $(p<0.05)$ and 14 year old groups $(p<0.01)$, while the mean value in 12-13 year old students is significantly higher than in the 14 year old group $(p<0.05$ in both comparisons).

The mean value for the dimension Psychological well-being in 10-11 year old children is significantly higher than in 13 year old $(p<0.05)$ and 14 year old schoolchildren $(p<0.05)$.

When it refers to the dimension Parents relations, the mean value in 10-11 year old children is significantly higher than in 12 year old $(p<0.01)$ and 14 year old groups $(p<0.01)$, as it is in the dimension School environment, with a significantly higher mean value than in the three groups of older age ( $p<0.01$ in all comparisons).

Table 5 shows the mean values for the dimensions, both for RSs and SWIs, per type of school.

The dimension with the highest score considering both types of scores was that of Peers in all types of schools. If we consider the RSs, the dimension with the lowest score in all schools was Psychological well-being; however, this changed when including weighting by importance, given that Physical well-being scored the lowest.

Considering RSs, when evaluating the mean differences in the dimensions by type of school, statistically significant differences were found in two dimensions. In the dimension Physical wellbeing $\left(F_{(2.595)}=3.87 ; p<0.05\right)$, the mean score of students from public schools was significantly lower than that of students who attend subsidized schools $(p<0.05)$. In the dimension School environment $\left(F_{(2.596)}=6.35 ; p<0.05\right)$, the mean value of students from subsidized schools was significantly higher than that of students attending public $(p<0.05)$ and private schools $(p<0.05)$.

Considering SWIs, the mean differences among types of schools were statistically significant in the Physical well-being dimension $\left(F_{(2.592)}=3.365 ; p<0.05\right)$, in which the mean in subsidized schools was significantly higher than in that of private schools $(p<0.05)$ and in the School environment dimension $\left(F_{(2.596)}=6.194 ; p<0.05\right)$, in which the mean in subsidized schools was significantly higher than in that of public $(p<0.05)$ and private schools $(p<0.05)$.

\section{DISCUSSION}

Quality of life assessment depends on the relationship between two factors: the assessment of the dimension as such, which implies a process of comparison; and the importance assigned to this dimension by an individual. ${ }^{26}$ In this framework, the present investigation was based on the following question: Are there any differences in the quality of life assessment when children have to score the importance of what is being asked to them? Since each individual assigns a different value to each domain of the daily life, we expected to find differences in the quality of life assessment when it is weighted by the importance assigned individually, leaving aside assumption that all standardized dimensions are equally important to all individuals. It is not possible to reply to this question in full based on the data collected, but they provide evidence that indicates, to a certain extent, that quality of life self-report results in children may vary when they weigh the importance of what is being asked to them, especially when stratified by gender and age.

No differences were found globally in the quality of life assessment regarding the dimensions with the higher scores when the value weighted by importance was included; however, there was a variation in the dimension that scored the lowest, i.e., that which was considered the worst, because by means of the assessment with traditional approaches, the one which is scored the lowest is the dimension Psychological well-being but when weighted by importance the dimension with the lowest score in all ages and in girls is Physical well-being.

This change in the lowest scored dimension 
only in girls implies the need to explore possible explanations based on gender, the importance given to various aspects of the daily life is different for boys and girls. Psychological well-being has been the dimension scoring the lowest and this could be explained by the fact that pre-adolescents go through a transition period during which they start shifting their ideas from concrete thinking to a more deductive, logical and abstract one ${ }_{,}^{27}$ with major questions related to life satisfaction and subjective well-being. On the other hand, the fact that when weighting the importance of a dimension, girls scored Physical well-being the lowest, this can be because the most relevant aspects of their daily life are especially associated with the relationships they have with others or with their emotional sphere. This is logical because, from an evolutionary standpoint, girls prioritize activities related to socialization, while boys usually focus on sports and physical activity. ${ }^{17}$ In addition, the emergence of secondary sex characteristics, and especially menarche, causes different health problems to girls, such as hormone disorders, and this also results in the fact that this dimension is assigned a lower score. ${ }^{28}$

In relation to age and type of school outcome measures at an overall quality of life level, the dimension with the lowest score in all types of schools and all age groups was Psychological wellbeing, but once values were weighted by importance, it changed to Physical well-being. It is likely that physical changes experienced at this age, such as the emergence of secondary sex characteristics, disturb pre-adolescents' relatively calm lifestyle and are the beginning of new ways of relating to the world, and new ways of thinking and feeling, ${ }^{29}$ making children feel greatly vulnerable, and this would even impact on their psychological well-being.

The dimension which scored the highest was Peers, a domain that acquires special relevance given the evolutionary stage, because development and integration into their social environment during childhood and especially adolescence are fundamental and it becomes more and more important as children grow up. The mean score in most of the dimensions assessed tends to reduce as age increases, and this proves that as children grow older, their mean quality of life is reduced in all dimensions. ${ }^{30}$

One of the limitations of this study is that the design was cross-sectional in which data are obtained at a specific moment, without considering factors that might have affected the assessment made by children regarding their quality of life; so, it would be important to conduct longitudinal studies to assess the consistency of these findings over time. Unfortunately we have not found other investigations in children using a similar methodology so as to compare results because studies focused on these processes are scarce and they are conducted on adults. ${ }^{31}$

\section{CONCLUSION}

Results mentioned above provide evidence with respect to the need to include importance weighting, especially when analyzing the dimension with the lowest scores in children in order to intervene in their quality of life, as this would allow to distinguish the particular needs of girls or of a specific age group, taking into account which dimensions are more and less important to children and focusing on them to achieve an effective and efficient intervention.

\section{REFERENCES}

1. The WHOQOL Group. The World Health Organization Quality of Life Assessment (WHOQOL): position paper from the World Health Organization. Soc Sci Med 1995; 41: 1403-09.

2. Urzúa A, Caqueo-Urízar A. Calidad de vida: una revisión teórica del concepto. Ter Psicol 2012; 30:61-71.

3. Quiceno J, Vinaccia S. Calidad de Vida relacionada con la salud infantil: Una aproximación conceptual. Psicología y Salud 2008;18:37-44.

4. Starfield B. Measurement of outcome: a proposed scheme. Milbank Mem Fund Q 1974;52:39-50.

5. Casas F. Las representaciones sociales de las necesidades de niños y niñas, y su calidad de vida. Anuario de Psicología 1992;52:27-45.

6. Wee HL, Chua HX, Li S.C. Meaning of health- related quality of life among children and adolescents in an Asian country: A focus group approach. Qual Life Res 2006;15: 821-831.

7. Rajmil L, Roizen M, Urzúa A. Calidad de Vida y Salud en Infancia y Adolescencia. Típica, Boletín Electrónico de Salud Escolar 2010; 6(2):244-9.

8. Urzúa A, Cortes E, Prieto L, Vega S, Tapia K. Autoreporte de la Calidad de Vida en Niños y Adolescentes Escolarizados. Rev Chil Pediatr 2009;80(3):238-244.

9. Urzúa A, Méndez F, Acuña C, Astudillo J. Calidad de Vida Relacionada con la Salud en Edad Preescolar. Rev Chil Pediatr 2010;81(2):129-138.

10. Urzúa A, Mercado G. La evaluación de la calidad de vida de los y las adolescentes a través del KIDDOKINDL. Ter Psicol 2008; 26(1):133-41.

11. Roizen M, Figueroa C, Salvia L, et. al. Calidad de vida relacionada con la salud en niños con enfermedades crónicas: comparación de la visión de los niños, sus padres y sus médicos. Arch Argent Pediatr 2007;105(4):305-313.

12. Cádiz V, Urzúa A, Campbell M. Calidad de Vida en niños y adolescentes sobrevivientes de leucemia linfoblástica aguda. Rev Chil Pediatr 2011;82:113-121.

13. Vidal A, Duffau G, Ubilla C. Calidad de vida en el niño asmático y su cuidador. Rev Chil Enf Respir 2007; 23: 160-166. 
14. Royer M, Bahamonde H, Mamani R, Rodríguez R, et aql. Calidad de vida pre y posadenoamigdalectomía en pacientes pediátricos. Rev Otorrinolaringol Cir Cabeza Cuello 2006;66:191-198.

15. SchwartzR,Sepúlveda J, Quintana T. Factores psicobiológicos en vitíligo infantil: Posible rol en su génesis e impacto en la calidad de vida. Rev Méd Chile 2009;137:53-62.

16. Berra S, Bustingorry V, Henze C, Díaz M, et al. Adaptación transcultural del cuestionario Kidscreen para medir calidad de vida relacionada con la salud en población argentina de 8 a 18 años. Arch Argent Pediatr 2009; 107:307-14.

17. Aymerich M, Berra S, Guillamón I, Herdman M, et al. Desarrollo de la versión en español del KIDSCREEN, un cuestionario de calidad de vida para la población infantil y adolescente. Gac Sanit 2005; 19:93-102.

18. Rajmil L, Serra-Sutton V, Estrada M, Fernandez de Sanmamed Guillamón I, et al. Adaptación de la versión española del Perfil de Salud Infantil (Child Health and Illnes Profile-Child Edition, CHIP-CE). Rev An Pediatr (Barc) 2004;60(06):522-9.

19. Sardón O, Morera G, Herdman M, Moreno A, et al. Versión española del TAPQOL: Calidad de vida relacionada con la salud en niños de 3 meses a 5 años. Rev An Pediatr (Barc) 2008;68(05): 420-4.

20. Serra-Sutton V, Herdman M, Rajmil L, Santed R, et al. Adaptación al español del cuestionario vecú et sante percue de 1 adolescent (VSP-A): una medida genérica de calidad de vida para adolescentes. Rev. Esp. Salud Pública 2002;76(006):701-712.

21. Urzúa A, Cortés E, Vega S, Prieto L, Tapia K. Propiedades psicométricas del cuestionario de auto reporte de la calidad de Vida KIDSCREEN-27 en adolescentes chilenos. Ter Psicol 2009;27(1):83-92.
22. Rajmil L, Roizen M, Urzúa A, Hidalgo-Rasmussen C, et al. Health-Related Quality of Life Measurement in Children and Adolescents in Ibero-American Countries, 2000 to 2010. Value Health 2012;15:312-22.

23. Ming $\mathrm{H}$. To weight: The role of dimension relevance in quality if life: Measurement. Soc Indic Res 2004;68:164-174.

24. Cohen J. A power primer. Psychol Bull 1992;112: 155-159

25. Ravens-Sieberer U,Auquier P, Erhart M, Gosch A, et al. The KIDSCREEN-27 quality of life measure for children and adolescents: psychometric results from a cross-cultural survey in 13European countries. Qual Life Res 2007;16(8):1347-1356.

26. Skevington S, O'Conell K, The WHOQOL Group. Can we identify the poorest quality of life? Assessing the importance of quality of life using the WHOQOL -100. Qual Life Res 2004;13:23-34.

27. IriarteF, Cantillo K, Polo A. Relación entre el nivel de pensamiento y el estilo cognitivo dependencia-independencia de campo en estudiantes universitarios. Psicología desde el Caribe 2000;(005):176-196.

28. Bisegger C, Cloetta B, Von Rueden U, Abel T, et al. Healthrelated quality of life: gender differences in childhood and adolescence. Soz.-Präventivmed. 2005;50:281-291.

29. Morgan I, Funke S. Pubertad. Secretaría de Salud. Dirección General de Planificación Familiar. Curso de orientación sexual y salud reproductiva 1992;55-7.

30. Bisegger C, Fuhr D, Michel G, Abel T, The KIDSCREEN Group. Age and gender differences in health-related quality of life of children and adolescents in Europe: a multilevel analysis. Qual Life Res 2009;18:1147-1157.

31. Bloem E, van Zuuren F, Koeneman M, Rapkin B, et al. Clarifying quality of life assessment: do theoretical models capture the underlying cognitive processes? Qual Life Res 2008;17:1093-1102. 